\title{
Los inicios de la industrialización en las Antillas Hispanas ${ }^{1}$
}

por

Oscar Zanetti Lecuona

Academia de la Historia de Cuba

A partir de la crisis mundial de 1929 la industrialización constituye la tendencia dominante en las economías latinoamericanas. Las Antillas hispanas no resultaron una excepción, pero en estas el proceso muestra interesantes particularidades, tanto respecto a lo que ocurre en el continente como en las islas entre sí. El desarrollo industrial que apenas se esboza en la década de 1930, gana entidad bajo los efectos de la II Guerra Mundial y se acelera bajo la égida estatal en la posguerra y la década de 1950, aunque con perfiles bien diferenciados en cada país.

Palabras clave: Antillas; República Dominicana; Puerto Rico; Cuba; industrialización; política económica; 1929-1960.

Bajo los efectos de la Gran Depresión en la década de 1930 y de la devastadora conflagración mundial que hubo de sucederla, el crecimiento de las economías latinoamericanas siguió una nueva tendencia. Desde las décadas finales del siglo XIX la modernización de la región había descansado en el sostenido incremento de sus exportaciones de productos básicos, así como en un parejo aumento de las importaciones destinadas a satisfacer necesidades de una población igualmente creciente. A partir de la crisis de 1929 la demanda de muchos de esos productos primarios se debilitó, originándose una generalizada caída de precios de muy negativo impacto sobre las balanzas de pago de los países de la América Latina. A continuación la II Guerra Mundial provocaría

1 El presente trabajo es un resultado parcial del proyecto HAR2012-37455-C03-01, "Marcadores del tiempo: continuidades y discontinuidades en las sociedades hispano antillanas, siglos XIX y XX”, coordinado por la Dra. Consuelo Naranjo Orovio. 
una severa contracción en los abastecimientos y otros bienes importados; aunque dicho fenómeno también propició una recuperación del sector exportador, su naturaleza transitoria vino a subrayar el agotamiento de una variante de expansión económica sustentada en las exportaciones tradicionales.

Ante las adversas circunstancias, las naciones latinoamericanas fueron adoptando medidas, en un principio pragmáticas y hasta improvisadas, con la finalidad de diversificar sus economías y hacerlas menos dependientes de las fluctuaciones y trastornos del mercado internacional. En el contexto de unas condiciones de vida deterioradas, primero por la crisis mundial y más adelante por las carestías que ocasionara la guerra, varias de esas acciones respondían a demandas populares incluidas en sus programas por movimientos políticos reformistas de perfil más o menos nacionalista. Al concluir la guerra, bajo los imperativos de la reconstrucción posbélica y de un proceso global de descolonización, los problemas del desarrollo económico adquirieron singular relevancia internacional, dando vida a disímiles interpretaciones y propuestas. En el marco de ese debate, e influidas en buena medida por los conceptos que sobre el desarrollo formulara la Comisión Económica para América Latina (CEPAL) - entidad creada como parte del flamante sistema de Naciones Unidas-, tomaron cuerpo las concepciones que habrían de trazar nuevas pautas al crecimiento de la economía regional. Dichas propuestas se caracterizaron por la absoluta prioridad otorgada a la industrialización en su calidad de gestora del desarrollo, ya que se le consideraba el vehículo idóneo para modernizar las sociedades y asegurar a Latinoamérica una ventajosa inserción en el comercio internacional, así como por el papel asignado al Estado en tanto agente propulsor de ese movimiento. A diferencia del antiguo modelo exportador, el crecimiento ahora sería «hacia adentro», orientado a la satisfacción de la demanda interna mediante una gradual sustitución de importaciones.

El proceso de industrialización dio lugar a un notable crecimiento económico en Latinoamérica, en el cual es posible diferenciar una primera etapa algo más lenta -durante la década del treinta y los años de guerra-, cuando el crecimiento regional apenas rebasó una tasa anual de un 2,6\%, seguida por un avance más acelerado $-5,5 \%$ anual- que desde el final del conflicto mundial se prolonga hasta 1980. Claro que es posible apreciar diferencias en el desenvolvimiento de dicha tendencia, tanto en sus diversas etapas como entre las naciones de la región, y no solo por sus distintos ritmos y alcance, sino hasta por los propios rasgos productivos del crecimiento, realidades a la luz de la cuales el concepto de «industrialización por sustitución de importaciones» no parece una generalización apropiada ${ }^{2}$.

2 Bértola y Ocampo, 2013: 170-171. 
En tal contexto la industrialización en las Antillas hispanas constituye un escenario peculiar. Ello obedece en primer término a las características de estos países, a su conformación insular con territorios y poblaciones relativamente pequeños, a sus economías formadas en buena medida desde la matriz de las plantaciones y estrechamente dependientes de Estados Unidos; condición esta última que también se proyectaba al plano político, hasta el extremo de que una de las islas -Puerto Rico- era de hecho una colonia norteamericana. Pero junto a esos rasgos compartidos, entre las naciones hispano-antillanas existían también apreciables contrastes, tanto por la complejidad de sus sociedades y sus diversas circunstancias políticas, como por las dimensiones y madurez de sus economías y, en particular, por el espacio que dentro de estas había ido ocupando el sector manufacturero. En virtud de tales condiciones, la industrialización en República Dominicana, Cuba y Puerto Rico muestra a la vez evidentes coincidencias y divergencias muy notables, realidades resultantes de movimientos históricos que desde una perspectiva comparada estas páginas se proponen explorar.

\section{CONDICIONES PREEXISTENTES Y REACCIONES INICIALES}

A diferencia de otros países latinoamericanos cuyo crecimiento «hacia afuera» se centró en la exportación de minerales o en productos agrícolas como el banano y el café, en las Antillas el auge exportador estuvo sustentado en un producto industrial, el azúcar, que pese a ser considerado en su forma cruda como una materia prima, es resultado de una manufactura que se fue mecanizando progresivamente hasta constituirse en una gran industria de producción continua. Incluso otro renglón de importancia en la exportación antillana, el tabaco, también puede considerarse parcialmente una manufactura ya que una porción de sus exportaciones consistía en un producto elaborado -el cigarro o puro-, en gran parte torcido a mano pero que al transcurrir el tiempo también se confeccionaría con máquinas, al igual que los cigarrillos.

Dicha realidad, que desde el punto de vista estadístico a veces impide apreciar con precisión la magnitud de la industria orientada hacia el mercado interno en las economías antillanas, ha actuado a lo largo del tiempo como una condicionante general del desarrollo de esta. Si por una parte la situación privilegiada del sector industrial «externo» en materia arancelaria, fiscal, financiera, etc., le permitió concentrar los recursos en detrimento de otras ramas de la industria y la agricultura, no es menos cierto que su expansión contribuyó a la acumulación de capitales, conformó mercados internos, creó infraestructuras, formó mano de obra calificada y propició la asimilación de 
innovaciones, factores todos de vital importancia para la aparición y el crecimiento de otras manufacturas. De hecho la formación del sector «interno» de la industria en las islas de matriz hispana, ocurre en estrecha relación con el extraordinario crecimiento productivo que desde finales del siglo XIX y durante el primer cuarto del XX originan las grandes inversiones en el área azucarera, determinantes para la definitiva transformación de dicha rama en una gran industria. Entre 1900 y 1929 la producción de azúcar en las tres Antillas hispanas casi se decuplica hasta totalizar 6,2 millones de toneladas, cifra que representaba la cuarta parte de todo el azúcar producido en el planeta. Asociado a ello se aprecia una pareja extensión de las vías férreas -hasta sobrepasar los $20.000 \mathrm{~km}$ en conjunto- y de otros medios de trasporte, la ampliación de antiguas instalaciones portuarias y la construcción de otras nuevas, el ensanchamiento de las áreas urbanas y su electrificación, además de un apreciable crecimiento demográfico, sobre todo de la población vinculada a las relaciones mercantiles ${ }^{3}$.

Es cierto que todo ello tuvo lugar bajo una omnipresente hegemonía norteamericana, pues el mercado de Estados Unidos era el único o casi único destino para los azucares de Cuba y Puerto Rico, aunque en menor medida para los dominicanos. Hacia 1925 los capitales estadounidenses ya habían llegado a controlar casi la mitad de los centrales azucareros puertorriqueños, dos tercios de los cubanos y el $90 \%$ de la industria del dulce en Santo Domingo, así como la mayor parte de los medios de transporte y comunicaciones, las redes eléctricas y otros componentes clave de la infraestructura de las islas. Dicha circunstancia generó una dependencia comercial que limitaba los efectos del crecimiento productivo para el desarrollo económico; ya fuese gracias a la incorporación al ámbito arancelario estadounidense en el caso de Puerto Rico, mediante un tratado de reciprocidad como el concertado con Cuba o por la administración implantada sobre las aduanas dominicanas, las importaciones de origen norteamericano pudieron enseñorearse de los mercados insulares. Dicha situación se agravaba debido a las prácticas monopólicas ejercidas por algunas grandes compañías azucareras extranjeras sobre el comercio al detalle en sus posesiones, las cuales propendían a la creación de compartimentos dentro de los mercados interiores de cada país en los cuales se favorecía la venta de mercaderías importadas.

A pesar de esas condiciones desventajosas, al sobrevenir los años de la Gran Depresión en los países hispano-antillanos se había formado un sector manufacturero orientado hacia los mercados internos, de dimensiones muy

${ }^{3}$ Un análisis detallado de la expansión azucarera y sus efectos puede encontrarse en Zanetti, 2012, cap. 2. 
variables según el caso pero con presencia suficiente para ocupar espacios apreciables dentro de la actividad económica. Ello era más notable en Cuba dadas sus dimensiones; desde la época colonial en la gran Antilla ciertas producciones artesanales habían comenzado a mecanizarse y agruparse en pequeños talleres, a la vez que algunos grandes comerciantes -en su mayoría inmigrantes españoles- se percataban de que varios de los artículos que importaban podían producirse localmente con mayores beneficios. Ocurrió así un paulatino ensanchamiento de la esfera productiva destinada al consumo interno, principalmente con la aparición de establecimientos dedicados a la elaboración de alimentos y bebidas - cerveza, hielo, pastas y otros-, la fabricación de papel, al aprovechamiento de la madera local para muebles y envases -particularmente de tabaco torcido-, así como a la producción de materiales de construcción, destilación de alcoholes o curtido pieles. En las primeras décadas del siglo XX, al calor de la vigorosa expansión azucarera, ese sector industrial amplió su espectro y sus escalas productivas mediante instalaciones dedicadas a la mezcla de abonos químicos y piensos, a la elaboración de oxígeno, de envases metálicos y de cartón, a las confecciones textiles, la fabricación de calzado y a la generación de electricidad, mientras que ciertos renglones de la producción alimentaria, así como la jabonería y perfumería, se integraban en grandes empresas y se incrementaba la producción de mosaicos, ladrillos y otros materiales constructivos, incluyendo el cemento para cuyo procesamiento se montó una moderna fábrica. En 1925 producían para el consumo nacional 740 establecimientos industriales ocupando en total algo más de 16.000 trabajadores, lo cual arrojaría un promedio de unos 20 trabajadores por instalación, por más que ese indicador resulta algo engañoso, pues junto a pequeños talleres cuasi artesanales se registraban plantas eléctricas, cervecerías y otras grandes fábricas en las que trabajaban varios cientos de operarios ${ }^{4}$.

Plenamente integrado al mercado norteamericano, en Puerto Rico esa presencia industrial resultaba inferior. Al igual que en Cuba, las mayores industrias de la isla eran las del azúcar y el tabaco, la primera con 41 fábricas, mientras que los talleres de la segunda -casi todos bajo el control de firmas estadounidenses- elaboraban en los años veinte algo más de 200 millones de puros, destinados en un $60 \%$ a la exportación. Sin embargo, la principal fuente de empleo -casi todo femenino- era la llamada «industria de la aguja», en realidad una extensa red de trabajo doméstico dedicada a la costura y el bordado que alcanzó su apogeo en los años de la I Guerra Mundial. A partir

${ }^{4}$ El número de establecimientos registrados en este informe de la Comisión de Estadísticas y Reforma Económica probablemente era inferior a la realidad. Para un análisis particular Marquéz, 2006: 54-62 y cuadro 1.4 del anexo. 
de entonces una parte de las trabajadoras comenzó a agruparse en talleres y hacia 1930 las exportaciones de esa rama manufacturera -muy vinculada a la industria de confecciones norteamericana-sobrepasaban los 15 millones de dólares. Ya fuese laborando individualmente o agrupadas, en la «industria de la aguja» encontraban empleo más de 40000 mujeres. Junto a estas ramas principales, los restantes rubros manufactureros se caracterizaban por la presencia de muy pequeñas instalaciones, quizás con la excepción de la industria alimenticia y en particular la elaboración de bebidas y licores, renglón en el cual se registra la instalación de dos fábricas de ron relativamente grandes en la década de $1930^{5}$.

Más atomizado era el sector manufacturero dominicano, pues si se exceptúan los 15 centrales azucareros que operaban en esa república, en el millar de establecimientos «industriales» registrados a mediados de la década de 1930 -tabaquerías, carpinterías, tejares, alambiques, fábricas de ron, de pastas y algunos otros alimentos, así como de jabón y almidón- laboraban como promedio menos de cinco trabajadores. El proceso más tardío y limitado de expansión azucarera, mayoritariamente concentrada además en el sudeste del país, y la débil infraestructura de transporte, conformaban un mercado interno fragmentado y de escasa demanda. Para colmo, las autoridades estadounidenses que en 1916 se hicieron cargo del gobierno de la República Dominicana tras ocupar el país, implantaron tres años después un arancel que eximía de cargos a 245 productos norteamericanos y reducía los derechos de otros 700, lo cual provocó la quiebra de numerosos talleres cuyas manufacturas no podían competir con los artículos provenientes de los Estados Unidos. A partir de 1924 el restablecido gobierno dominicano, urgido de colectar fondos para el servicio de una agobiante deuda, comenzó a gravar con impuestos de consumo algunas importaciones, medida que hasta cierto punto surtía un efecto protector sobre los productos homólogos locales, pero los funcionarios designados por Washington para supervisar el fisco dominicano no tardaron en considerar que dichos tributos operaban como un arancel complementario y exigieron hacerse cargo de su cobro ${ }^{6}$.

Al iniciarse la década de 1930 la industria, al igual que las restantes ramas de las economías antillanas, experimentó los severos efectos de la depresión. La fuente de los desequilibrios se hallaba en el sector azucarero, cuya crisis no puede considerarse una mera repercusión del fenómeno mundial desatado a partir del crac de Wall Street en 1929. Desde algunos años antes la progresiva recuperación de la producción europea de azúcar de remolacha de

5 Dietz, 1989: 131-137. Sobre la «industria de la aguja»: Baerga, 1993.

${ }^{6}$ Moya Pons, 1992: 1-15. 
las devastaciones ocasionadas por la guerra mundial comenzó a saturar los mercados, cuya demanda a raíz del conflicto habían venido cubriendo otros productores. Ello originó una declinación de precios agravada muy pronto por las medidas proteccionistas de algunos grandes consumidores, en particular Estados Unidos. Dicha conducta, unida a otros factores, hizo que la crisis afectase de manera desigual a las naciones antillanas, pues mientras Cuba reducía su producción azucarera en más de un $60 \%$ al verse esta desplazada del mercado norteamericano, Puerto Rico se beneficiaba de las medidas proteccionistas y mantenía sus zafras en ascenso hasta alcanzar un record de 900.000 t.m. República Dominicana, cuyo azúcar ya había sido apartado del consumo estadounidense desde años antes, pretendió aprovechar la política restrictiva que Cuba y otros grandes exportadores adoptaron para sostener los precios y en 1932 incrementó su producción, pero casi de inmediato se vio obligada a recular ante la debilidad de la demanda en el mercado mundial. Lo que si sufrieron las tres islas por igual fue el desplome del precio, pues en 1932 la libra del dulce llegaría a cotizarse a medio centavo de dólar.

El impacto sufrido por las economías básicamente monoproductoras de las Antillas fue terrible, todavía más debido a la contracción simultánea de los renglones secundarios de exportación. El café puertorriqueño, que ya venía decayendo, no consiguió recuperarse de un terrible huracán en 1930, de manera que por el resto de esa década sus producciones apenas representarían un $10 \%$ de lo cosechado en la etapa anterior. Tendencia similar siguió el tabaco, cuyas exportaciones menguan en casi dos tercios, mientras la industria del aguja -que parece haber corrido mejor suerte- reportaba también menores ingresos al verse afectada por drásticos recortes salariales. En Santo Domingo los jornales agrícolas de la caña se redujeron casi a la mitad, a la vez que se elevaba el precio de algunos consumos esenciales; si en la sociedad dominicana el impacto depresivo no tuvo peores efectos fue porque en ella subsistían zonas relativamente amplias apenas tocadas por la modernidad capitalista. Por el contrario, en la economía cubana -carente de renglones capaces de compensar el enorme retroceso del azúcar- la crisis se despliega en círculos concéntricos hasta configurar el más severo cuadro de contracción en Latinoamérica. Con exportaciones cuyo valor en 1933 era un $70 \%$ inferior a lo exportado en 1929, e importaciones por solo \$ 42 millones, se estima que el Ingreso Nacional cubano había disminuido ese año en más de un $40 \%$ respecto al nivel medio de los años veinte. En correspondencia con ello las recaudaciones del Estado se redujeron hasta determinar severos recortes al presupuesto, lo cual trajo aparejadas la cesantía de jornaleros y la acumulación de varios meses de adeudos en el pago a los empleados. Según los estimados, en la fase más aguda de la depresión un tercio de la fuerza 
laboral de Cuba se hallaba desempleada y los que conservaban sus ocupaciones percibían salarios bastante disminuidos.

Como cabe esperar, semejante fenómeno tuvo trascendentales repercusiones sociales y políticas. En Cuba la dictadura de Gerardo Machado fue derribada por una huelga general, a la cual sucedió una volátil situación de la cual emergería un gobierno provisional de corte revolucionario que representaba un serio reto a la dominación norteamericana. Si ese proceso no llegó a más, fue porque la división entre las fuerzas políticas de orientación progresista permitió una restauración parcial del orden oligárquico, de la mano de los militares de bajo rango que habían asumido el mando del ejército. Los trastornos ocasionados por la crisis condicionaron en la República Dominicana la deposición de Horacio Vázquez, primer presidente electo al terminar la ocupación norteamericana. Tras este movimiento se hallaba el jefe del Ejército, general Rafael Leónidas Trujillo, quien meses después alcanzaría la presidencia de la República inaugurando una prolongada tiranía. Las centrales azucareras de Puerto Rico, no obstante su expansión productiva, aprovecharon la crisis para aplicar rebajas salariales hasta el punto que el ingreso de sus trabajadores en 1932 había disminuido un 30\% respecto al nivel de 1929. Como dichas medidas coincidían con un creciente desempleo ocasionado por la contracción de otras ramas, así como la disminución de los ingresos en la industria de la aguja, la «isla del encanto» se hundió en una pavorosa situación social. Las consecuencias no se hicieron esperar y entre ellas la más trascendente sería una huelga azucarera que durante varias semanas paralizó a las centrales del país en 1934.

La reacción ante la trágica situación en Borinquén hubo de concretarse en las aplicaciones locales del New Deal, el plan concebido por la administración de Franklin D. Roosevelt para enfrentar la crisis en los EE. UU. Dicho esquema se extendió a la isla mediante programas especiales de asistencia social y reconstrucción económica, pero esas acciones se revelaron insuficientes para modificar el tétrico panorama. En busca de soluciones más eficaces se constituyó entonces una comisión compuesta principalmente por jóvenes políticos e intelectuales del Partido Liberal de la isla, fervorosos partidarios del «Nuevo Trato» que habían estrechado relaciones con personalidades prominentes del entorno rooseveltiano. Su propuesta fue el «Plan Chardón», -denominado así por su principal gestor, el rector de la Universidad de Puerto Rico, Carlos Chardón- , vasto proyecto que proponía una reorientación de la economía boricua fundamentada en la industrialización y en una agricultura diversificada. El eje de dicho programa radicaba en la redistribución de la propiedad agraria y el reordenamiento de la industria azucarera, la cual era objeto de un generalizado repudio por la indiferencia de sus propietarios «absentistas» 
ante la miseria que padecía la sociedad insular. La estricta aplicación de una antigua e incumplida disposición que establecía un límite de 500 acres a la extensión de las propiedades rurales, permitiría repartir tierras a los campesinos desposeídos, a lo cual habría de sumarse la adquisición de una o más centrales por el Estado cuya operación sirviese de índice para establecer precios y controlar la transferencia de ganancias por parte de las compañías absentistas, para acumular así recursos con los cuales impulsar la industrialización del país. Puesto en práctica mediante la creación de la Puerto Rican Reconstruction Administration, el plan Chardón se vio obstruido de inmediato por los intereses azucareros, cuyas intrigas y manipulaciones terminarían por empantanarlo. Aunque la P.R.R.A. obtuvo logros apreciables en materia de electrificación y obras de infraestructura, así como en la reducción del desempleo, el resultado global de sus acciones quedó muy lejos de las transformaciones proyectadas, circunstancia que serviría de asidero al grupo de jóvenes liberales liderados por Luís Muñoz Marín para formular las tesis reformistas del nuevo Partido Popular Democrático ${ }^{7}$.

Para asegurar la tranquilidad social en República Dominicana, Rafael Leónidas Trujillo no escatimó acciones represivas contra sus adversarios, pero supo valerse también de recursos populistas y ganar así cierto respaldo a su régimen. Concediendo algunas de las pequeñas demandas planteadas por los trabajadores, el dictador en ciernes logró controlar las embrionarias organizaciones sindicales. Medidas tendientes a evitar la elevación de los precios de los artículos básicos de consumo, permitieron mantener los salarios en torno al nivel de subsistencia y garantizar costos remunerativos a los centrales azucareros y otras empresas del país. Con indiscutible habilidad, Trujillo manipuló contra los inmigrantes las aprensiones que las crisis suelen despertar -enconadas en el caso dominicano por las históricas desavenencias con el vecino haitiano- dando forma a un curioso nacionalismo impregnado de tintes racistas. Primero mediante una la ley de «dominicanización del trabajo» que obligaba a las empresas a emplear un $70 \%$ de trabajadores nativos y más adelante desatando una verdadera masacre de inmigrantes haitianos, el dictador puso a su merced la satisfacción de la demanda de una mano de obra de la cual las compañías azucareras no podían prescindir. El autoritario Estado trujillista comenzó a moverse entonces hacia el control de esa principal industria, cuyos recursos eran vitales para asegurar el servicio de una gravosa deuda que era fuente de injerencias por parte de Washington. Pero como la caída

7 Un penetrante análisis del trasfondo político de todo este proceso lo ofrece Pantojas, 1990: 36-38. González, en su tesis doctoral, (2000: 247-273), analiza el Plan Chardón, así como la reacción de la Asociación de Productores de Azúcar de Puerto Rico frente a este. 
en el valor de las exportaciones generaba un sensible déficit en la balanza de pagos, el gobierno trujillista optó por restringir el consumo de importaciones a la vez que impulsaba su sustitución, lo cual dio lugar en la agricultura a la distribución de algunas tierras estatales, mientras que se promovían las manufacturas mediante una ley de Franquicias Industriales y otras iniciativas destinadas a fomentar las producciones artesanales y facilitar la instalación de algunas fábricas ${ }^{8}$. Fue esta una política de éxito muy relativo, si se tiene en cuenta que en 1939 las tres «grandes» fábricas no azucareras del país empleaban en conjunto menos de 500 trabajadores, pero serviría al dictador para desviar una parte de los fondos públicos hacia la creación de empresas personales -como la Compañía Salinera-, en una manifiesta tendencia hacia el manejo indiferenciado de la Hacienda nacional y su economía privada que devendría elemento característico de la economía quisqueyana.

El desplome de la producción azucarera que postró a la economía cubana impulsó la búsqueda de alternativas al fatídico monocultivo. Aunque diversas en su formulación, las propuestas giraban en torno al concepto de la «diversificación». Convertida en un componente clave de la ideología económica en el país, la diversificación era un concepto bajo el cual se propugnaba desde el simple estímulo a los cultivos de subsistencia hasta los más ambiciosos planes de industrialización, contando con tantas acepciones como intereses se hacían sentir en el seno de la sociedad. De hecho los primeros pasos en ese sentido los había dado el dictador Machado, quien ante la necesidad de restringir la producción azucarera adoptó una política compensatoria que incluía la puesta en vigor de un arancel de sentido proteccionista. Bajo el amparo de ese arancel se consolidaron algunas producciones agrícolas, como el café, y se realizaron también inversiones en la industria láctea, las grasas comestibles y la rama textil -entre otras-, empresas que en varios casos no consiguieron sobrevivir al casi inmediato impacto de la crisis que redujo prácticamente a la mitad el índice global de las manufacturas no azucareras. Para enfrentar la depresión el gobierno apostó por recuperar a la producción azucarera mediante una reforma de las relaciones comerciales cubano-norteamericanas; con otra perspectiva, las organizaciones opositoras se pronunciaban por cambios de mayor alcance en la estructura económica, medidas orientadas hacia la diversificación productiva en cuya formulación y aplicación concedían creciente protagonismo al Estado.

Sin embargo, con el regreso al poder de las fuerzas oligárquicas tras el fracaso del movimiento revolucionario, se impuso la alternativa de la recupe-

${ }^{8}$ Quizás el resultado más efectivo de dicha política fue la formación de una estadística industrial, al quedar obligados a registrarse los establecimientos comerciales e industriales que operaban en el país. Moya Pons, 1992: 13-17. 
ración azucarera, sustentada en el régimen de cuotas que implantó en 1934 el gobierno de Washington. Aunque la fracción del consumo concedida a Cuba resultaba bastante inferior a la tradicional, el nuevo sistema establecía un atractivo precio preferencial para cuyo disfrute resultaba necesario renegociar el tratado de reciprocidad comercial. El nuevo convenio reafirmó las ventajas arancelarias para el azúcar cubano y otros pocos productos, a cambio de mayores concesiones a las mercaderías estadounidenses. Estas ganaron así en competitividad frente a rivales importados de Europa y Japón, pero también devinieron poderosos contrincantes de la producción para el consumo local, incluso en manufacturas ya enraizadas como los cigarrillos. Finalmente, el restablecimiento del modelo económico tradicional se impuso como fórmula para salir de la crisis, situación que aceptaría con resignación la naciente burguesía industrial cubana ${ }^{9}$. En 1937, bajo los efectos de la reanimación de las exportaciones, la producción industrial no azucarera conseguía recuperar el nivel previo a la crisis pero su crecimiento posterior apenas alcanzaría un $4 \%$, enmarcada en una política, más redistributiva que desarrollista, cuyas bases consolidaría la constitución aprobada en 1940.

De tal suerte, la nueva tendencia económica que durante los años treinta se perfilaba en varios países de América latina, en las Antillas hispanas apenas consigue esbozarse, con mayor o menor claridad según los casos pero sin trascender los límites de un proyecto.

\section{LA COYUNTURA BÉLICA}

La fuerte demanda ocasionada por la II Guerra Mundial condujo a la plena recuperación de las exportaciones azucareras antillanas, solo que dicho efecto tardó algo en hacerse sentir, en parte por las dificultades de transporte que entrañó la guerra submarina. Mucho más inmediata fue la contracción de las importaciones, que afectó seriamente el aprovisionamiento de alimentos y otros bienes de consumo, propiciando el crecimiento de algunas producciones sustitutivas. Dadas las circunstancias, dicha tendencia contaría ahora con un promotor inusual, pues Estados Unidos, deseoso de aliviar sus compromisos

9 Fundada en 1923, la Asociación Nacional de Industriales de Cuba se mostró relativamente activa en la promoción de los intereses de la industria durante los años de crisis, pero su directiva terminó por aceptar las condiciones impuestas por el tratado comercial, convencida de que la reanimación de la demanda interna, indispensable para potenciar la actividad manufacturera, dependía de la recuperación del azúcar. Marquéz, 2006: 278-291. 
de abastecimiento, alentó a sus socios comerciales antillanos al desarrollo de las producciones domésticas.

El impacto de la guerra en el comercio importador cubano se registra sobre todo a partir de 1942, con la entrada de los EE. UU. -y de Cuba como su aliada - en la contienda mundial. En 1943 el déficit en las importaciones de combustibles y materias primas, así como de bienes manufacturados era de un 22,4 y un $17 \%$ respectivamente, -algo inferior, entre un 8 y $10 \%$ en los alimentos- proporción que se acentuó al año siguiente y no comenzaría a ceder hasta $1945^{10}$. Como en ese mismo lapso el valor de las exportaciones casi se duplica -hasta $\$ 409$ millones en 1945 -, en virtud de la compra global e ilimitada de las zafras adquiridas a un precio fijo por una entidad norteamericana, la restricción en materia de importaciones vino a coincidir con un alza notable en el consumo, tanto más porque las disposiciones gubernamentales respecto al salario acrecentaron el poder adquisitivo de los trabajadores ${ }^{11}$.

La respuesta del Estado cubano a semejante coyuntura fue el incremento de sus regulaciones sobre la actividad económica mediante la creación de una serie de organismos - Junta de Economía de Guerra, Comisión de Fomento, Oficina de Regulación de Precios y Abastecimientos, entre otros-, con el objetivo de controlar la inflación y promover la producción nacional. Un «Programa de Guerra» formulado por el gobierno de Fulgencio Batista en 1942 proyectaba proteger a la industria y la agricultura para propiciar así la sustitución de importaciones, a la vez que se proponía controlar los precios, regular las relaciones laborales y abrir fuentes de empleo. En materia agrícola dicha orientación dio lugar a una ley de Cultivos Obligatorios con la cual se pretendía incrementar la producción de alimentos aprovechando tierras baldías, acción que sin contemplar cambios en la estructura de propiedad agraria se dio de narices con los intereses azucareros, empeñados en ampliar sus plantaciones para satisfacer la creciente demanda. En el aspecto industrial se promulgaron sendas leyes, una de «industrias de guerra»y otra para «industrias nuevas», otorgando a las empresas creadas -o ampliadas- bajo su amparo exenciones arancelarias para la importación de maquinaria y materias primas, así como un ventajoso tratamiento fiscal. El estímulo que ello representaba se vería coartado, sin embargo, por la casi simultánea concesión de franquicias aran-

${ }^{10}$ Alienes, 1949: 148.

11 Anuario Azucarero, 1959: 24. Las compras de azúcar las realizo una corporación paraestatal a precio inferior al del mercado mundial, pero Washington era el único cliente capaz de adquirir semejantes volúmenes y, sobre todo, transportarlos. Las importaciones se mantuvieron deprimidas hasta 1944, pero al año siguiente su crecimiento respecto al nivel de preguerra $-80 \%$ - era muy cercano al del valor total de las exportaciones. 
celarias para las importaciones de alimentos y otros bienes de consumo, así como por una ley de Ampliación Tributaria que fijaba nuevos gravámenes a los capitales y utilidades, a la vez que incrementaba los impuestos de consumo a varios renglones - cigarrillos, refrescos, cervezas, etc.- de la industria nacional. Ante tan contradictorio despliegue de medidas, la Asociación de Industriales manifestó sus críticas por lo que creía una innecesaria proliferación de regulaciones estatales, a la vez que insistía en la necesidad de una reforma general del arancel y la creación de una banca central que movilizase el crédito, entre otras demandas puntuales de estímulo a la producción manufacturera ${ }^{12}$.

Las limitaciones derivadas de un contexto estructural inalterado, así como las incoherencias de sus políticas, lastraron la eficacia del Estado cubano como impulsor del desarrollo en una coyuntura indiscutiblemente complicada, pues si de un lado la guerra disminuía la competencia del comercio importador, por otro imponía carencias en la adquisición de bienes de capital y materias primas indispensables para el crecimiento de la producción industrial. Esta aumentó entonces más como resultado del déficit de importaciones que de la efectividad de las medidas de estímulo, de manera que si en los años iniciales del conflicto mundial pareció estancarse en torno un índice de 42,2, en 1945 asciende hasta un 62,8, lo cual representa un incremento de casi un tercio ${ }^{13}$. Los avances eran muy notables en renglones ya consolidados como la cerveza y los refrescos, los cigarrillos, el calzado o el cemento, pero resultan también significativos en los tejidos de algodón, rubro más reciente cuya producción se duplica entre 1939 y 1944. También crecieron en magnitud considerable ciertas producciones destinadas a la exportación, entre estas varias derivadas de la industria azucarera como alcohol, rones, licores y caramelos -artículos demandados por Estados Unidos-, pero también otros más novedosos, cual fueron los casos de los medicamentos y la talla de diamantes, actividad esta última que por las circunstancias bélicas se trasladó a La Habana desde su sede habitual en Holanda. Como resultado de las políticas de estímulo se instalan unas cincuenta industrias, entre «nuevas» y «de guerra», incluyendo fábricas de neumáticos, cristalería, tejados de asbesto-cemento y productos químicos. Por lo general se trataba de fábricas mayores a la media de la planta industrial preexistente, si se tiene en cuenta que cada una empleaba, como promedio, casi un centenar de trabajadores. Cierto número de estas empresas eran subsidiarias de firmas norteamericanas -Goodrich S. A., Goodyear Tires

12 Marquéz, 1994: 17-23, ofrece un sucinto análisis de ese proceso.

13 Pérez-López, 1977: 37-72. El índice calcula el valor global de la producción a precios constantes de 1952, con base 100 en 1953. En las referencias a incrementos productivos por renglones se trata de volúmenes. 
and Rubber, National Crystals, entre otras- que se acogieron a las ventajas de la estimulación industrial e instalaron fábricas relativamente modernas, aunque tampoco faltaron casos en que se emplearon tecnologías cuyo costos de producción solo dejaban un aceptable margen de beneficio por las excepcionales condiciones del mercado, situación que compartían muchas de las antiguas industrias.

Al igual que en Cuba, durante la II Guerra Mundial la producción industrial dominicana se vio estimulada por el aumento en la demanda de azúcar y mieles, cuyas compras masivas a precio fijo fueron también centralizadas por una firma para-estatal, aunque en su caso anglo-norteamericana. El incremento en el valor de las exportaciones en un 154\% entre 1939 y 1945 posibilitó una mejoría en los ingresos, de la cual también se beneficiaron, aunque en pequeña medida, los trabajadores vinculados al sector externo. Ese y otros factores propiciaron un fortalecimiento de la demanda en circunstancias en que la severa restricción de importaciones favorecía a la producción de consumo nacional. Sin embargo, las limitaciones para la adquisición de medios de producción y la escasez de financiamiento determinaron que esa demanda fuese cubierta en su mayor parte por la producción artesanal. Al menos eso cabe deducir del hecho de que el número de establecimientos registrados casi se duplique-desde 1660 en 1939 hasta 2998 en 1946- mientras se mantiene igual o incluso decrece el capital medio de estos -7500 pesos promedio-; lo que sí parece haber aumentado, en cambio, es la tasa de ganancia de esos productores -particularmente los mayores- debido a la inflación ${ }^{14}$.

Junto a las condiciones creadas por la coyuntura, en 1940 tuvo lugar un acontecimiento político de gran trascendencia económica: la firma del Tratado Trujillo-Hull, que devolvió las aduanas y la soberanía fiscal al Estado dominicano. Dicho convenio, unido a la adquisición -al año siguiente- de la sucursal local del National City Bank, posibilitaría la implementación de una política de estímulo al sector interno de la economía, en la cual habrían de conjugarse la prohibición de las exportaciones de ciertos bienes de consumo, la reducción de aranceles a materias primas y maquinaria y la exención de impuestos a nuevas inversiones. Tal sistema de controles, manejado arbitrariamente, potenciaría el enriquecimiento de Trujillo y su familia mediante el cobro de comisiones por las licencias de importación o el monopolio en la venta de ciertos renglones. La paralela imposición de un gravamen a la exportación de azúcar - progresivo en relación con el precio-, permitiría al Estado captar un parte sustancial del incremento de los ingresos por tal concepto, recurso que

14 Otro índice elocuente, el promedio de trabajadores empleados por establecimiento, se mantuvo muy cercano a 5. Cassá, 1982: 283 y tabla IV-2. 
sería utilizado sobre todo para amortizar la deuda externa, pero que también contribuyó a la acumulación de capitales por parte del dictador.

El enunciado del artículo 90 de la nueva Constitución aprobada en 1942, según el cual podría estimularse a las empresas que beneficiasen a la economía nacional, dio pie a la adopción de un sistema de contratos para promover industrias dedicadas a la sustitución de importaciones. A tenor de dicho instrumento, que entre otros privilegios otorgaba exenciones arancelarias para la importación de utillaje y materias primas, fue creada la Textilera Dominicana -controlada por la familia Armenteros-, así como una fábrica de cemento y la Chocolatera Sánchez, inversiones estas últimas realizadas con fondos estatales que transcurrido cierto tiempo terminaron en manos de Trujillo y sus asociados ${ }^{15}$. Como resultado de la apertura de esas empresas mayores, en los años de la inmediata posguerra se observa un incremento en la capitalización de los establecimientos manufactureros -hasta una media de 10300 pesosque, unido a la posterior concentración que se refleja en el número de estos, constituyen un buen indicio de que el proceso de industrialización dominicano comenzaba a tomar cuerpo.

En 1940 triunfa en las elecciones de Puerto Rico el Partido Popular Democrático, cuyo programa, inspirado en el fallido plan Chardón, postulaba la reforma agraria y la industrialización como bases del desarrollo. La victoria «popular» se vio reforzada a los pocos meses con el nombramiento como gobernador de Rexford Tugwell, un rooseveltiano de izquierda convencido de que las reformas eran imprescindibles para mantener a Puerto Rico en manos norteamericanas. Una ley de Tierras aprobada en 1941 permitió finalmente expropiar los terrenos que excediesen del famoso límite de los 500 acres, a partir de lo cual comenzaron a distribuirse solares a «parceleros», así como fincas de hasta 10 hectáreas a campesinos e incluso transformar algunas plantaciones en cooperativas. En el aspecto industrial, el programa reformista descansó en la creación -en 1942- de la Compañía de Fomento de Puerto Rico, respalda por un Banco de Fomento creado poco después; ambas instituciones serían orientadas por una Junta de Planificación constituida coincidentemente para el diseño de la política económica. El «Fomento»-como se conocería al ente industrializador- fue dotado con un presupuesto anual de medio millón de dólares y la posibilidad de emitir bonos o tomar préstamos de fuentes privadas para financiar sus proyectos, los cuales -de acuerdo con la propia ley que creó la entidad-consistirían en instalaciones de industria ligera orientadas hacia el mercado insular. Con esa línea de acción definida, las primeras inversiones de la corporación fueron una industria papelera y otra de vidrio, destinadas a

15 Moya Pons, 1992: 27-38, desarrolla un interesante análisis de algunos de esos contratos. 
proveer insumos indispensables - cajas y botellas-a la producción de ron, cuyo auge extraordinario bajo las circunstancias bélicas venía proporcionando una parte sustancial de los recursos con que el gobierno de la isla sustentaba sus programas. Otras industrias «fomentadas», como la de artículos de cerámica, la de calzado y una fábrica textil, se proponían sustituir importaciones vitales que la guerra había tornado deficitarias ${ }^{16}$.

Este programa se desarrolló en el contexto de agudas carestías, pues el aprovisionamiento desde fuentes continentales parece haber sido aún más precario en Puerto Rico que en las islas vecinas. Entre 1941 y 1942 el valor de las importaciones se redujo en más de un 35\% -a pesar del aumento de precios-, mientras que la conexión marítima con los puertos norteamericanos quedó prácticamente interrumpida durante los primeros meses de 1943. Las consecuencias de esa contracción fueron muy severas, pues a la vez que el déficit de alimentos disparaba la inflación, la carencia de insumos reducía la actividad económica hasta el punto de que en 1942 el desempleo afectó al $37 \%$ de la fuerza laboral. Al igual que sus vecinas, Borinquén se benefició de la reanimación de la economía azucarera, pero en su caso no tanto por la posibilidad de acrecentar la producción -que de hecho se estanca y hasta retrocede en algún año-, sino por el aumento de precios, que en su caso fue superior al de Cuba y se vio reforzado incluso en 1945 mediante incentivos. Sin embargo, el mayor importe al ingreso boricua provino de los fondos federales, primero por los gastos derivados de la construcción de bases militares y algunos programas sociales, los que en 1942 y 1943 generaron empleos para 36.552 personas, y después por los beneficios que reportó la exportación de ron, cuya demanda en los Estados Unidos se triplica hasta superar los 17 millones de galones debido al déficit de otros licores. Sin embargo, más que los ingresos reportados por la venta de ron, el verdadero provecho de ese comercio provenía del mecanismo de devolución del impuesto federal que gravaba la bebida a razón $\$ 4.00$ por galón -más 30 centavos adicionales por calidad-, lo cual reportó ingresos al fisco puertorriqueño por algo más de 65 millones de dólares en $1944^{17}$.

Dichos recursos financieros resultaron vitales para el desarrollo del programa industrial, toda vez que las expectativas de participación privada en las inversiones del Fomento apenas se concretaron. En el caso de la fábrica de vidrios, a las compañías roneras - principales consumidoras potenciales de sus botellas- se les ofrecieron acciones por $\$ 2,5$ millones, de las cuales en un inicio se comprometieron a suscribir títulos por 300.000 dólares, compromiso

16 Pantojas, 1990: 42-44.

17 Bolívar, 2007-2008: 207-257. 
que al cabo de un año solo se había concretado en un monto de 178.000. Es cierto que apenas inaugurada la fábrica de vidrio se vio afectada por una huelga que dilató su entrada en producción, razón por la cual sus clientes cancelaron sus órdenes de compras e importaron 65.000 cajas de botellas de los Estados Unidos. Pero superado dicho conflicto la industria del ron mantuvo su esquiva conducta alegando que la fábrica no disponía del surtido de botellas requerido. Esa situación y otras parecidas, como la enfrentada por la fábrica cartonera, eran testimonio de la renuencia del sector privado boricua a colaborar con las iniciativas del Fomento, actitud que la Asociación de Industriales de la isla -constituida en 1930- se encargó de hacer patente en reiteradas críticas. La industria privada se quejaba del tratamiento dado por el gobierno a las compañías del Fomento, a las cuales otorgaba exenciones fiscales y otros beneficios que creía debían extenderse a todo el sector manufacturero, a la vez que condenaba el exclusivismo de la compañía estatal que se reservaba el $51 \%$ de las acciones de todas las empresas que promovía; el programa industrial, alegaban, intentaba movilizar los capitales locales pero manteniéndolos en una posición subordinada. Apartado el sector privado de las iniciativas del Fomento, cuyas producciones de hecho saboteaba, el presidente de dicha entidad. Teodoro Moscoso, solicitó en 1944 un financiamiento de 30 millones de dólares para poder materializar sus proyectos. El PPD que tras una nueva victoria electoral controlaba ahora las dos cámaras del legislativo, consiguió que la legislatura otorgase una asignación de 13 millones que, sumados a un financiamiento previo de $\$ 5$ millones concedido por el Banco de Fomento, totalizaron los 18 millones con los cuales la Compañía de Fomento pudo concluir la fábrica de cartón y construir otras de tejidos, productos cerámicos y levaduras sintéticas, así como instalar un aserradero y un matadero industrial, inversiones todas en las cuales, terminada la guerra, encontraban empleo apenas un millar de trabajadores ${ }^{18}$.

Desde esta perspectiva, la importancia del programa de industrialización boricua parece sobredimensionada, por más que a él deba acreditarse también la creación de cierta infraestructura y la capacitación de fuerza de trabajo, aprovechadas en fases posteriores del crecimiento industrial. Pero es sin dudas la circunstancia haber constituido el primer plan de desarrollo protagonizado por el Estado en la región lo que le ha otorgado su relevancia histórica. Sin embargo, las bases de ese plan resultaban muy frágiles, en tanto dependían de las posibilidades financieras del gobierno local, las cuales terminada la guerra disminuirían considerablemente al desplomarse las ventas de ron. En

18 Bolívar, 2012: 323-348, ofrece una visión de conjunto relativamente detallada de este proceso. 
una posición igualmente delicada se encontraban algunos de los progresos manufactureros de las otras Antillas, conseguidos gracias a las excepcionales condiciones que creara la conflagración mundial en los mercados insulares de manufacturas.

\section{EL PROTAGONISMO ESTATAL Y SUS VARIANTES}

La conflagración mundial concluyó con la rendición de Japón en 1945, pero sus efectos sobre los mercados habrían de prolongarse por algunos años más. Para las Antillas hispanas, la primera y más contundente evidencia del retorno a la normalidad fue la reimplantación del régimen de cuotas azucareras por Estados Unidos en enero de 1948; decisión por demás decepcionante, pues las esperanzas que Cuba y Dominicana albergaban de ver retribuida con un aumento de cuotas su «abnegada cooperación» se vieron defraudadas. Los azucareros cubanos tuvieron que contentarse con cubrir los eventuales aumentos el consumo norteamericano, mientras que para los dominicanos solo se abría la posibilidad de satisfacer el margen no cubierto por Cuba. Aunque la reconstrucción europea y la guerra de Corea sostuvieron la demanda y el precio durante una breve etapa, la saturación del mercado y el desplome de las cotizaciones en 1952 demostraron cuan ilusorias eran las perspectivas de una expansión sustentada en la exportación de azúcar. La alternativa que se perfilaba como más eficaz era la industrialización por sustitución de importaciones, entonces en pleno auge en Latinoamérica continental.

En Puerto Rico, donde con mayor coherencia se había probado esa fórmula, sus resultados parecían poco satisfactorios. El programa industrial del Fomento enfrentaba crecientes dificultades; además de la limitada creación de empleos, salvo la fábrica de cemento todas las plantas en operación arrojaban pérdidas y debían sostenerse a partir de un presupuesto público cuyos ingresos decrecían. La renuencia del empresariado local a adquirir esas producciones se acentuó al normalizarse el comercio importador, poniendo de manifiesto que el pequeño mercado boricua, en la práctica una extensión del norteamericano, carecía de los mecanismos de protección indispensables para la industrialización sustitutiva. El clima de la posguerra tampoco resultaba favorable; con la política rooseveltiana en retirada y Tugwell sustituido como gobernador, desde Washington soplaban los vientos de la «guerra fría» que tornaban sospechoso de socializante a todo intervencionismo estatal. La tendencia internacional hacia la descolonización, a la cual EE. UU. no podía sustraerse, abría la posibilidad de que Puerto Rico fuese independiente, con lo cual quedarían cortadas sus ventajosas relaciones económicas con la 
metrópoli. Ante semejante disyuntiva, Muñoz Marín y la dirigencia del PPD optaron por dejar a un lado sus devaneos nacionalistas y desenterraron una propuesta autonómica que incrementaba las prerrogativas del gobierno local, aunque renunciando a toda pretensión de soberanía.

En tales circunstancias el programa industrial experimentó un notable viraje. La iniciativa partió del propio Fomento -siempre bajo la dirección de Moscoso-, que a principios de 1946 formuló una propuesta para atraer capitales de inversionistas norteamericanos. Esta hubo de concretarse al año siguiente mediante una ley de Incentivos Industriales, la cual fue ampliada en 1948 para extender el límite temporal de las exenciones contributivas, que en algunas ramas llegarían a ser totales. Al mismo tiempo, el gobierno anunció su decisión de privatizar las fábricas de la Compañía de Fomento. Se iniciaba así el proyecto conocido como «Operación Manos a la Obra» ${ }^{19}$.

El papel de la industrialización como eje del desarrollo, dada su capacidad de creación de empleo y el mayor impacto que tendría en el nivel de vida de la población, se potenciaba en el nuevo programa, opción que haría patente además el paulatino abandono de la política agraria inicialmente impulsada por el P.P.D. En su nueva modalidad los factores locales del crecimiento industrial -recursos, capitales y empresarios- eran sustituidos por los estadounidenses, al tiempo que el limitado mercado insular se relegaba a un papel secundario; el esfuerzo productivo se orientaría ahora hacia el vasto consumo metropolitano tratando de sacar el mayor provecho a la especial relación que mantenía la isla con los Estados Unidos. El gobierno puertorriqueño continuaría desempeñando un papel muy activo en todo el proceso, pero ya no como inversionista o planificador, sino como promotor, mediante la realización de obras de infraestructura y otras acciones complementarias y, sobre todo, proveyendo un «ambiente» atractivo al capital foráneo cuyas empresas serían eximidas de impuestos durante una década. Para dirigir e impulsar la «operación», en 1950 se creó una Administración de Fomento Económico, con oficinas en las principales ciudades de EE. UU., que actuaría como enlace con los potenciales inversionistas, mientras que la antigua Compañía de Fomento quedaba reservada para la construcción de «facilidades» y el adelanto de préstamos. Al ceder la iniciativa inversionista al capital metropolitano, el PPD terminaba ajustándose a las relaciones habituales entre el Estado y el mundo de los negocios en los Estados Unidos ${ }^{20}$.

19 Baver, 1993: 13-16.

${ }^{20}$ Curet, 2003: 21-23. Para movilizar hacia la Isla a los capitales acumulados en EE. UU. durante la guerra, la campaña promocional debía informarles no solo de las ventajas fiscales ofrecidas, sino también de las facilidades de acceso al mercado continental. 
La nueva política tuvo muy notables y casi inmediatos resultados. En el verano de 1950 ya había 80 nuevas fábricas operando en la isla y dos años después, al proclamarse el Estado Libre Asociado, su número se acercaba a 170. A partir de ahí el proceso de industrialización avanzó con rapidez: en 1963 el número de establecimientos fabriles instalados bajo el programa ya ascendía a 632 , de las cuales el $90 \%$ era de empresarios norteamericanos. Como resultado de ello, y de inversiones paralelas en la hotelería, el comercio y otras ramas, así como del notable auge constructivo, el PIB boricua se duplicó en una década, elevándose desde \$723, 9 M en 1950, hasta \$1 691,9 M en 1960. Según puede apreciarse en la tabla 1, tan rápido crecimiento hizo de la industria el mayor sector de la economía insular; en 1963 aportaba el 23\% del ingreso neto de la isla, proporción que representaba más que el doble del peso de la agricultura. La mayor parte de esa planta industrial fue fruto de inversiones «intensivas en trabajo», que habían sido atraídas no solo por los incentivos fiscales sino por el bajo nivel de los salarios. Si atendemos a la inversión media por unidad fabril -\$524.000 en 1956-, se trataba de fábricas medianas, principalmente de la rama textil y de confecciones, del calzado, artículos de plástico, electrodomésticos y otros bienes de consumo, las cuales por lo general importaban su maquinaria e insumos y exportaban su producción al continente, de manera que sus eslabonamientos con la economía insular eran escasos, ya que incluso desde el punto de vista fiscal el aporte era poco significativo ${ }^{21}$.

Según datos de 1964, la industria se había convertido en la mayor fuente de empleo, ya que en dicho sector laboraban 105.000 trabajadores, 72.000 de ellos en fábricas promovidas por el Fomento. Este, sin embargo, era un logro relativo, pues a pesar de ello y del incremento paralelo de las ocupaciones en la construcción $-62 \%-\mathrm{y}$ la administración pública $-37 \%-$, los puestos de trabajo creados no compensaban los desaparecidos en la llamada «industria de la aguja» $y$, sobre todo, en la agricultura, sector este último que experimentó una reducción de 90.000 trabajadores. El éxito incuestionable de la «Operación Manos a la Obra» en materia de crecimiento económico, contrasta así con sus limitaciones en la generación de empleo, pues el número de desempleados apenas se redujo en los años 50 -de hecho creció entre 1950 y 1955-, de manera que si la presión social no se acrecentó, fue porque casi medio millón de puertorriqueños emigró en esa década para trabajar en la metrópoli ${ }^{22}$. Aunque

${ }^{21}$ Wells, 1969: 151-153. Al comenzar la década de 1960, la inversión media había aumentado hasta \$ 812.000 por fábrica, en gran medida debido al establecimiento de subsidiarias de grandes firmas norteamericanas como Union Carbide, General Electric y W. R. Grace.

${ }^{22}$ En la industria de la aguja desaparecieron 40.000 empleos y el número de personas empleadas se redujo en 60.000 entre 1950 y 1960. Ayala, 1966: 75-85. 
Tabla 1. Puerto Rico: composición del PROducto nacional Bruto POR SECTORES $(\%)$

\begin{tabular}{|l|c|c|}
\hline \multicolumn{1}{|c|}{ Sector } & $\mathbf{1 9 5 0}$ & $\mathbf{1 9 6 0}$ \\
\hline Agricultura & 17.5 & 9,8 \\
\hline Manufactura & 15,9 & 21,9 \\
\hline Construcción y minería & 4,0 & 6,0 \\
\hline Transporte y otros serv. públicos & 8,1 & 9,3 \\
\hline Finanzas, seguros, etc. & 9.9 & 11,8 \\
\hline Servicios & 5,9 & 8,4 \\
\hline Gobierno & 10,0 & 11,2 \\
\hline Otros & 28,7 & 21,6 \\
\hline
\end{tabular}

Fuente: Dietz, James L., Historia económica de Puerto Rico, Río Piedras, Huracán, 1989, tabla 3.1.

insuficientes, los empleos creados vieron crecer su remuneración; entre 1952 y 1963 el monto de los salarios pagados en el sector industrial se triplicó, no solo por el incremento numérico de los trabajadores, sino por el aumento del salario real promedio desde $\$ 18$ a $\$ 44$-de $\$ 12$ a $\$ 37$ en el caso de las mujeres-, tendencia que parece haberse generalizado en el país si nos atenemos al crecimiento global de dicho indicador a una tasa anual de 8,4\%. El progreso que ello representó en el nivel de vida no solo se reflejó en indicadores como el PIB per cápita -de $\$ 342.00$ en el año 1950 a $\$ 716.00$ en el año 1960-, sino que también se tradujo en avances de otros importantes indicadores como la esperanza de vida, que aumenta hasta los 69 años, el analfabetismo -reducido a $17 \%-$, así como en la disponibilidad y calidad de la vivienda.

Si se le compara con la industrialización que tenía lugar paralelamente en otros países de Latinoamérica, orientada principalmente hacia la sustitución de importaciones, el proceso puertorriqueño reviste una indiscutible singularidad, pues apenas seis años después de iniciada la Operación Manos a la Obra, el 53\% de la producción industrial de la isla se destinaba al mercado norteamericano. Como la mayoría de las empresas importaban sus insumos y la creciente demanda de la población se satisfacía con una elevada proporción de artículos importados -las importaciones de bienes de consumo duradero crecieron en 430\% entre 1948 y 1963-, el coeficiente de importación de la isla representaba el $50 \%$ de su PIB, mientras que el de las exportaciones lle- 
garía hasta un 38\% en 1963. La situación resultaba así bien distinta a la de los países industrializados de América latina, entre los cuales el de más alto coeficiente de importaciones -Chile- apenas rebasaba un 10\%. Como resultado de ello en la balanza de pagos se triplicó el saldo negativo en la cuenta de bienes y servicios entre 1950 y 1960, tendencia que se compensaba en el balance general gracias al aumento de los ingresos por concepto de remesas de la emigración boricua, así como por las transferencias de fondos del gobierno federal. El movimiento de capitales tenía un efecto parecido, pues si la inversión directa resultó en la mencionada década algo superior a \$600 millones -la mitad de ella, aproximadamente, destinada a la industria-, las ganancias que reportaba tendían a fugarse con rapidez, según lo indican los pagos por concepto de rendimiento de capital que en el año 1961 ascendieron a 127 millones de dólares. Dicho fenómeno, unido al crecimiento de las importaciones, esbozaba una tendencia por demás alarmante ${ }^{23}$.

Al transformar la estructura de la economía, la fórmula de «industrialización por invitación» -como se la calificaría- aplicada en Puerto Rico dio un trascendental impulso a la modernización de la sociedad. No obstante, su dependencia del bajo salario y los atractivos fiscales, así como las limitaciones en la creación de empleo y el desfavorable sesgo de las finanzas exteriores, creaban cierto margen de incertidumbre acerca de la sostenibilidad de dicho proceso.

El crecimiento industrial en República Dominicana seguiría un curso singular, determinado por el absoluto control de Trujillo sobre el aparato estatal y la irrefrenable codicia del dictador. Si la coyuntura creada por la guerra mundial propició la definitiva articulación de los mecanismos en que habría de sustentarse la dinámica económica del país, los ingresos generados por el auge exportador de la posguerra vinieron a nutrir al proyecto económico trujillista con las reservas necesarias para que este extendiese sus tentáculos. Seducido por el ascenso del precio del azúcar en los años cuarenta, el "Generalísimo» decidió incluir a ese sector fundamental en el ámbito de sus negocios. Mientras mantenía a la producción azucarera bajo una presión fiscal que la tornaba poco remunerativa, el dictador inició discretamente sus inversiones con la instalación de un pequeño ingenio -Catarey- en 1948; tres años después decidía subir la parada fomentando Rio Haina, que aspiraba a convertir en la mayor fábrica de azúcar en la isla. A estos sumaría poco después cuatro ingenios comprados a pequeños propietarios y, en 1956, otros cinco centrales mayores, adquiridos de entidades norteamericanas. En menos de una década, Trujillo lograba hacerse con el control de las tres cuartas partes de la industria del

${ }^{23}$ Pantojas, 1990: 75-76. Baquero, vol. 8, 1964: 5-13. 
dulce. Dicha circunstancia permite comprender por qué, aún en una coyuntura de precios poco estimulantes, la producción azucarera dominicana se duplica hasta alcanzar el millón de toneladas al finalizar los años cincuenta ${ }^{24}$.

Lejos de limitarse al mundo del azúcar, las ambiciones empresariales del «Generalísimo» se desplegaron simultáneamente hacia otros terrenos no menos gananciosos. El proceso de sustitución de importaciones iniciado durante la guerra y continuado al término de esta mediante el sistema de contratos, a partir de 1950 alcanza una nueva dimensión con la promulgación de otra ley de Franquicias Industriales y Agrícolas. La intención primordial de esta era proteger las inversiones azucareras de Trujillo, a las cuales se otorgaron de inmediato los beneficios estipulados en dicha legislación, pero también iba más allá y con el deseo expreso de promover la inversión de capitalistas nacionales y extranjeros se ofrecían a estos garantías de que tendrían «...el derecho a conservar siempre la dirección y administración de sus empresas...» y que no se les impondrían restricciones para la exportación de sus beneficios o capitales. Para consolidar un favorable clima inversionista se procedió a fortalecer la institucionalidad económica mediante el perfeccionamiento de la Secretaria de Estado a cargo de los asuntos industriales, la cual experimenta diversos ajustes a lo largo de la década de 1950, así como con la regularización del sistema de registros -comercial, industrial, etc.- y el mejoramiento de las estadísticas. La culminación de dicho proceso, ya al iniciarse los años sesenta, sería la creación de una Comisión de Planeamiento encargada de diseñar un «plan maestro» para la gradual industrialización del país ${ }^{25}$.

Concluida la favorable coyuntura que creara la Guerra de Corea, se acentuó la política encaminada a la sustitución de importaciones, elevando los aranceles sobre algunas mercaderías hasta el punto de hacer su compra insostenible, al mismo tiempo que se manejaba el régimen tributario y el recurso de los subsidios para, ya fuese mediante el sistema de contratos o con concesiones especiales, movilizar los capitales acumulados durante los años de bonanza azucarera. Como resultado de estas medidas se desarrolla un proceso de instalación de nuevas industrias; varias vinculadas a las actividades agrícolas -una mezcladora de fertilizantes, aserraderos, despulpadoras de café, plantas de vegetales en conserva o procesadoras de madera deshidratada y bagazo de caña-, otras destinadas a proveer gravilla, tejas de asbesto-cemento, mosaicos y demás materiales de construcción, así como fabricas de zapatos, jabón, papel y distintos bienes de consumo. Un número apreciable de estas inver-

${ }^{24}$ Zanetti, 2012: 255-257.

25 El Plan Maestro debía ejecutarse en colaboración con el sector privado, o por el Estado en el caso de que este se mostrase reticente. Moya Pons, 1992: 41-42 y 62-65. 
siones respondía a la iniciativa de extranjeros -radicados o no en República Dominicana-, en muchos casos asociados con la familia Trujillo o estimulados personalmente por el dictador. Un caso paradigmático es el del empresario textil salvadoreño Elías Gadala María, a quien Trujillo «conquistó» para que se hiciese cargo de una fábrica de sacos construida con fondos estatales que operaba con grandes pérdidas, ofreciéndole plenas exenciones impositivas y arancelarias. Después de sacar a esa fábrica de la quiebra, Gadala rescataría otra empresa que fabricaba botellas para la cervecería del dictador, hasta conseguir, finalmente, materializar el sueño del «Generalísimo» de una producción textil integrada que partiendo del fomento de las plantaciones de algodón, llegase hasta la hilandería y la fabricación de tejidos ${ }^{26}$.

A lo largo de los años cincuenta la inversión industrial dominicana crece y se concentra, pues mientras que el número de instalaciones - no azucareras- se reduce de 3398 en 1950 a 2411 en 1960, el capital invertido aumenta desde 40 hasta 120 millones de pesos y casi se duplica el número de trabajadores, cuyo promedio llega a superar los 10 empleados por establecimiento. En comparación con lo que hasta entonces existía, la nueva planta manufacturera se caracterizaba por fábricas algo mayores, aunque la pequeña y mediana empresa continuó desempeñando un papel fundamental en la producción y el empleo. Por ramas, los crecimientos más notables se registran en textiles, productos químicos y tabaco, aunque también es apreciable en el calzado, las confecciones y las bebidas, cuya capitalización crece menos, pero experimentan una importante reducción en el número de establecimientos. En líneas generales, la planta industrial dominicana continuaba siendo una manufactura de artículos de elaboración sencilla y fácil consumo, pues la estrechez del mercado constituía una de sus mayores limitaciones, al extremo de que para asegurar la demanda a ciertas empresas del «Benefactor», como la fábrica de calzado FADOC o la de pintura PIDOCA, se apelaba a procedimientos tan pintorescos como prohibir andar descalzo en lugares públicos $\mathrm{u}$ obligar a que se pintasen las casas dos veces por año ${ }^{27}$.

Como puede apreciarse en la tabla 2, el crecimiento es notable en términos de valores producidos, pero no entrañó un cambio en la composición de la producción. Un resultado complementario de todo este proceso fue la aparición de una suerte de empresariado dominicano -que también incluía inversionistas

${ }^{26}$ Gadala se convirtió así en el mayor empresario del país después de Trujillo, pero sus éxitos se vieron a la postre contenidos por los celos de otros empresarios y, sobre todo, de Ramfis, el hijo de Trujillo quien se había iniciado como inversionista con la instalación de un gran molino de trigo y una papelera. Croes, Edwin, "Nacimiento, auge y colapso de la industria textil dominicana", Hoy (digital), (Santo Domingo, 9 de enero de 2010). Moya Pons, 1992: 51-58.

27 Cassá, 1982: 302-304. 
Tabla 2. República Dominicana. Composicion de la produccion industrial. PRINCIPALES RAMAS (\% DEL tOTAL DE VALORES PRODUCidos)

\begin{tabular}{|l|c|c|}
\hline \multicolumn{1}{|c|}{ Ramas } & $\mathbf{1 9 5 0}$ & $\mathbf{1 9 6 0}$ \\
\hline Alimentos & 26,4 & 33,5 \\
\hline Azúcar y derivados & 38,7 & 36,9 \\
\hline Bebidas y tabaco & 14,5 & 10,2 \\
\hline Textil, confecciones y cuero & 6,0 & 5,4 \\
\hline Madera y muebles & 3,0 & 1,4 \\
\hline Papel e impresos & 1,6 & 1,8 \\
\hline Químicos & 2,9 & 5,1 \\
\hline Productos de piedra y cristal & 2,6 & 1,1 \\
\hline Maquinaria y metalurgia & 0,3 & 0,6 \\
\hline Energía eléctrica y combustible & 2,1 & 3,2 \\
\hline Otros & 1,8 & 0,2 \\
\hline
\end{tabular}

Fuentes: Calculado a partir de 1950: Cassá, Roberto, 1982, tabla IV-5. Tamames, Ramón, La República Dominicana y la integración económica de América Latina, Buenos Aires, Banco Interamericano de Desarrollo, 1968, anexo 2.

extranjeros- en cuyo centro figuraba Trujillo, «señor de vidas y haciendas» que concedía su protección y favores a quienes se le asociaban o al menos no interferían con sus intereses. El círculo de negocios del Generalísimo era tan extenso como impreciso, pues amplios segmentos se confundían con la Hacienda pública y muchas de sus empresas aparecían a nombre de familiares o testaferros. Al morir el dictador en 1961, se calcula que a su nombre o el de su familia figuraban 119 compañías, las cuales abarcaban el 80\% de la actividad económica en la capital del país -entonces llamada Ciudad Trujillo-, a la vez que tenía participaciones más o menos cuantiosas en otras 55 corporaciones, entre las cuales no solo figuraban industrias, sino también compañías de transporte, constructoras, hoteles, firmas importadoras, bancos y hasta aseguradoras; ello sin contar las propiedades rurales que según algunos abarcaban casi la mitad de la tierra cultivable ${ }^{28}$. La avaricia y los afanes mo-

\footnotetext{
28 Wiarda, 1968: 83-85.
} 
dernizadores del «Generalísimo» habían dado lugar a un insólito desarrollismo, cuyos beneficios eran a la vez palpables y relativos, pues buena parte de los capitales acumulados por el dictador y su familia se hallaban depositados en el extranjero.

La posguerra tuvo en Cuba efectos contrapuestos: si por una parte la producción de azúcar consiguió sobrepasar sus máximos históricos, diversos renglones de la agricultura y la industria que habían prosperado en la coyuntura bélica se vieron perjudicados al normalizarse la concurrencia. Producciones como el alcohol, los caramelos y algunos licores, que se colocaban con buenos dividendos en los mercados exteriores, así como otras posesionadas en el mercado interno -calzado, aceite de maní, confecciones textiles, artículos de vidrio y ciertos medicamentos-, comenzaron a sufrir los embates de la competencia y entraron en un proceso recesivo, matizado por la reducción de operaciones y el cierre de fábricas. Los empresarios, que por lo general operaban con una baja productividad, reaccionaron solicitando protección al gobierno, que apenas podría brindarla sin enfrentar muy serias complicaciones. Las ayudas usuales, ya fuese la elevación de aranceles, la supresión de cargas fiscales o las rebajas salariales, al implementarse afectarían los intereses de los comerciantes importadores, de las colectividades obreras, de la burocracia pública y hasta de la imponente burguesía azucarera, sectores todos cuya airada reacción podía darse por descontada. Con tan cerrado margen de maniobra, a finales de los cuarenta la sociedad cubana se convirtió en escenario de enconados debates.

El más sonado de aquellos foros fue la Conferencia para el Progreso de la Economía Nacional, convocada en octubre de 1948 por las asociaciones de industriales y comerciantes para presentar propuestas al nuevo gobierno encabezado por Carlos Prío Socarrás, el segundo líder del Partido Revolucionario Cubano -auténtico- que asumía la Presidencia de la República. En correspondencia con los intereses de sus promotores, la Conferencia, proclamó a la inversión privada como fuente de toda dinámica económica, relegando aparentemente al Estado a un rol secundario. Sin embargo, el Estado resultaba ser protagonista predilecto de la declaración final, pues la mayoría de sus recomendaciones se referían a las tareas que el ente público debía acometer. Además de crear el clima apropiado para los negocios, entre las responsabilidades del gobierno figuraban una reforma fiscal que desgravase las actividades productivas, la creación de un Banco Central e instituciones oficiales de crédito, el fomento del turismo, así como el establecimiento de un órgano coordinador de la política comercial. Tampoco faltaban las advertencias contra el excesivo intervencionismo en el terreno laboral, a la vez que se clamaba por la introducción de regulaciones disciplinarias y fórmulas expeditas de despido. Con ese punto de vista coincidiría un par de años después la misión del Banco 
Internacional de Reconstrucción y Fomento, invitada por el gobierno cubano como paso previo a la concertación de un empréstito. El análisis de la misión reconocía que la economía cubana se hallaba en un «círculo vicioso» debido a la excesiva dependencia del azúcar, pero su examen de los problemas apenas trascendía el plano de lo funcional, mientras que las recomendaciones seguían el camino ya trillado de la diversificación productiva, el ensanchamiento de mercados para la exportación, los estímulos a la inversión y la flexibilización de las regulaciones laborales ${ }^{29}$.

Las dificultades para articular una política de desarrollo en el caso de Cuba no estribaban tanto en la identificación de carencias o el enunciado de sus remedios, como en la imposibilidad de llegar a un consenso social en torno a las acciones a emprender y la escasa capacidad gubernamental para ejecutarlas. La propia actividad de la administración Prío lo evidenciaba: creó el banco de emisión y redescuento -Banco Nacional de Cuba- así como un Banco de Fomento Agrícola e Industrial (BANFAIC) para financiar la diversificación productiva, pero los beneficios que esa última entidad podía reportar se vieron limitados por su conservadora gestión. En el plano comercial se firmó un convenio exclusivo con los Estados Unidos en el marco del GATT que prolongaba la dependencia derivada del viejo régimen de la reciprocidad, para después negociar en condición subordinada una puntual protección arancelaria a los textiles y algún otro renglón abatido por la competencia de las importaciones. Carente de sistematización, la actividad gubernamental se desplegaba además en medio de la corrupción más desfachatada, de manera que la estabilidad económica debía atribuirse más que todo a la bonanza propiciada por el conflicto coreano.

En 1952, cuando esa guerra se aproximaba a su fin, el golpe de estado del general Fulgencio Batista dio un fatídico vuelco a la situación del país, quebrando el orden constitucional justo cuando se realizaba una zafra cuyo extraordinario monto contribuiría a desplomar el precio del azúcar. Para sostenerlo se retornó a la formula de la restricción productiva, cuya aplicación ocasionaría una pérdida de casi \$250 millones en el valor de las exportaciones durante el trienio 1953-1955. Ante el deterioro generalizado de los indicadores económicos, el gobierno de Batista apeló al gasto público, primero mediante un empréstito interior y, finalmente, con la formulación de todo un «plan de

29 La misión del Banco Mundial fue encabezada por el norteamericano Francis A. Truslow; su extenso informe puede verse en Banco Internacional de Reconstrucción y Fomento, 1951. Las recomendaciones de la Conferencia para el Progreso... en Conferencia para el progreso de la economía nacional, 1949, cap. III. Marquéz, 1994: 32-39, hace un examen general de estos y otros proyectos. 
desarrollo económico y social». La base del ambicioso proyecto eran los capitales acumulados durante la guerra y la posguerra, para cuya movilización se apeló a procedimientos compulsorios, forzando la adquisición de valores públicos por parte de la banca privada. Con tales recursos se constituyó una red de instituciones financieras paraestatales que, en conjunto, extendieron créditos por más de 1.250 millones de pesos durante los siete años de dictadura. Pero el desarrollismo en el proyecto batistiano - de inspiración keynesiana- se caracterizó por el predominio del financiamiento a obras y servicios públicos sobre las inversiones reproductivas, esfera esta última en la cual el turismo ostentaba absoluta primacía. Del inmenso caudal de fondos canalizado por la banca oficial, la industria no azucarera recibió poco más del $10 \%$, evidencia de la escasa prioridad concedida al incremento y diversificación de la producción nacional. Para estimular la inversión de capitales extranjeros se apeló a la fórmula de las industrias mixtas, remedo -a pequeña escala- de la «industrialización por invitación» puertorriqueña, solo que en el caso de Cuba, carente de la ventaja de exportación a los Estados Unidos, su destino era un mercado nacional con limitadas posibilidades de protección. En la aplicación de esa política se llegaría hasta financiar con el crédito público la expansión de grandes corporaciones norteamericanas como la Standard Oil o la American Foreign Power. Aunque probablemente lo peor eran los frecuentes drenajes de capital hacia las arcas de los principales personeros gubernamentales, que además de enriquecerse intentaban monopolizar importantes renglones de la economía ${ }^{30}$.

En parte por el estímulo estatal, aunque más que todo gracias a iniciativas privadas, la manufactura experimenta un sostenido crecimiento durante estos años. Entre 1946 y 1958 la producción no azucarera crece a un ritmo anual de $5,7 \%$, de manera que según algunos estimados casi duplica su monto total. El sector energético ostenta la primacía; a la única refinería existente -que se amplía- se unen otras dos instaladas a finales de los años cincuenta, mientras que la generación de electricidad en 1958 asciende hasta 1463 millones de kwh, lo cual casi triplicaba lo generado en 1946. Como la rama más dinámica de la economía en esos años era la construcción, la producción de materiales se incrementa consistentemente; la de cemento al doble $-715.000 \mathrm{tm}$ en

${ }^{30}$ Como resultado del derrame de recursos sobre sectores mayoritariamente improductivos, esta política de «gasto compensatorio» deterioró aún más la balanza de pagos e hizo descender las reservas en divisas desde 532,2 M de dólares en 1951 hasta 77,4 M. en 1958. Cuba, Ministerio de Hacienda, 1959: 80-82. Un testimonio justificativo de esa política lo ofrece Martínez Sáenz, 1959. Para un balance crítico de la gestión económica del régimen batistiano, Pino Santos, 2001: 177-180. 
1958-, pero también la de cabillas corrugadas y otras estructuras metálicas, para cuya producción se inaugura en 1958 una siderurgia de capital mixto. Un año antes entraba en producción la primera fábrica de alambres eléctricos, inversión extranjera que contó con un financiamiento del BANFAIC. Es también notable la expansión en la producción de neumáticos, que se triplica en la década de 1950, así como la de papel -aumenta en 50\%-, que casi al finalizar esta etapa incluye las primeras producciones realizadas a partir de bagazo de caña. En la rama alimenticia -la de mayor volumen después de azúcar- destacan los lácteos, con un crecimiento cercano al 90\% entre 1950 y 1958, aunque en bebidas y licores la tendencia resulta bastante más pausada, pues el ron y los refrescos apenas crecen, mientras la cerveza aumenta solo un $25 \%$. Los tejidos de algodón, cuya producción experimenta una contracción en los primeros años cincuenta, solo en 1958 consigue recuperar la cifra de 12 millones de kilogramos producida en 1950; algo parecido ocurre en el calzado que solo a finales de la etapa llegará a superar -y por un pequeño margen- los niveles de posguerra ${ }^{31}$.

Aunque varias de las industrias fomentadas en la década de 1950 eran relativamente grandes, al finalizar esta no llegaban a veinte -excluidos los centrales azucareros- las que empleaban más de 500 trabajadores; aún incluyendo a la industria azucarera, el promedio general apenas superaba los 50 trabajadores por fábrica, claro indicio de la persistencia de una amplia franja semiartesanal según puede apreciarse en la tabla 3. La sustitución de importaciones parece efectiva en algunos renglones como el cemento y otros materiales de construcción, así como en los neumáticos, el papel y la jabonería, pero estas últimas eran industrias con una alta proporción de materias primas importadas, por lo cual más que una sustitución generaban una permuta de importaciones. Como el crecimiento fue comparativamente menor en el sector de bienes de consumo, las importaciones en esa esfera se mantuvieron relativamente altas, y todavía más en el rubro de alimentos ya que, salvo los lácteos, se acrecienta su importación, en buena medida debido al lento crecimiento de la producción agrícola -y a su pobre articulación con la industria-, en la cual solo el arroz aumenta en una escala notable. De hecho ramas como la del calzado y la industria fosforera que cubrían la demanda nacional, fueron reguladas por el Estado para impedir la sobreproducción y el cierre de talleres -en muchos casos artesanales-, lo que abrió cierto margen a las importaciones. Otro pro-

31 Otros renglones no resultan tan afortunados, pues la producción alcoholera en 1958 se hallaba a poco más de la mitad de lo realizado durante la guerra. Pérez-López, 1977: 53-54, apéndice A, proceden también los estimados de crecimiento global, que otras fuentes expresan en términos más modestos. 
TABla 3. Cuba: industria y EMPLeO, 1954

\begin{tabular}{|l|c|c|}
\hline \multicolumn{1}{|c|}{ Número de empleados } & Establecimientos & \% \\
\hline 5 o menos & 830 & 45,1 \\
\hline 6 a 10 & 333 & 18,2 \\
\hline 11 a 25 & 320 & 17,3 \\
\hline 26 a 100 & 250 & 13,6 \\
\hline 101 a 250 & 67 & 3,6 \\
\hline 251 a 500 & 26 & 1,4 \\
\hline Más de 500 & 14 & 0,8 \\
\hline Total & 1840 & 100 \\
\hline
\end{tabular}

Fuente: U. S. Department of Commerce: Investment in Cuba, Washington, Government Printing Office, 1956. (Basado en el Directorio industrial publicado por el BANFAIC en 1954).

blema del desarrollo industrial cubano era su distribución espacial, pues el $70 \%$ de la industria se concentraba en la capital; tendencia persistente si se tiene en cuenta que de las 221 fábricas en construcción o en proyecto entre 1952 y 1956, 149 se instalarían en La Habana ${ }^{32}$.

El desarrollo industrial -no azucarero- cubano entre 1948 y 1958 se verifica a un ritmo similar al de algunos países latinoamericanos en fase de expansión, como México, Perú o Colombia, e incluso supera a otros que con una industria ya establecida experimentaban dificultades -Argentina y Uruguay, por ejemplo-, pero respecto a sus hermanos antillanos marchaba con relativa lentitud. Es cierto que la circunstancia excepcional de Puerto Rico posibilita el portentoso crecimiento de una manufactura orientada a la exportación, mientras que el punto de partida dominicano es tan bajo que distorsiona las proporciones. En el caso cubano, sin embargo, se observa cierto extravío de propósitos, pues el crecimiento ni apunta de manera coherente a la sustitución de importaciones, ni presenta alternativas de exportación capaces de compensar el manifiesto desequilibrio de la balanza de pagos. Con sus vecinos antillanos Cuba compartía un bajo nivel de integración industrial, lo cual limitaba los

32 En 1956, mientras la industria del calzado se mantenía «estabilizada», se registra la importación de 422.000 pares de zapatos. Los datos sobre la ubicación de las fábricas en Revista del Banco Nacional de Cuba, La Habana, Julio de 1956: 6. 
eslabonamientos indispensables para hacer de la industria el genuino motor del desarrollo económico.

En medio de una indiscutible diversidad de situaciones, un factor común se hace visible durante la etapa inicial de la industrialización antillana: el Estado, que se perfila como un actor de creciente protagonismo por más que sus marcadas diferencias en cada país determinen distintas actuaciones. Así, en el caso puertorriqueño su rol se ciñe al de coordinador y promotor, participación que no obstante resulta decisiva para el ritmo y la envergadura que alcanzará el proceso industrializador. En República Dominicana la imbricación de los negocios familiares de Trujillo y la gestión gubernamental era tal, que resulta difícil precisar el desempeño del Estado, algo que sin embargo comenzará a mostrarse con claridad a principios de la década de 1960, cuando la confiscación de los bienes de la familia Trujillo de lugar a un sector estatal mayoritario en la economía dominicana. El Estado cubano era el que parecía menos involucrado -al menos directamente- en las gestiones de industrialización, a pesar del «plan de desarrollo» y los financiamientos otorgados por la dictadura batistiana. Sin embargo, una vez derrocado ese régimen por una revolución en 1959, y al tomar esta un rumbo socialista, toda la industria de Cuba pasa a manos del Estado que se encargaría de trazar las pautas para su desarrollo.

\section{BiBLIOGRAFÍA}

Alienes, Julián, Economía de posguerra y desempleo, La Habana, 1949.

Ayala, César, "The Decline of Plantation Economy and the Puerto Rican Migration of the 1950's", Latino Studies Journal, 7/1 (New York, 1966): 75-85.

Anuario Azucarero de Cuba, 1959, La Habana, Cuba Económica y Financiera.

Baerga, María del Carmen (ed.), Género y trabajo: la industria de la aguja en Puerto Rico y el Caribe hispánico, San Juan, Editorial de la Universidad de Puerto Rico, 1993.

Baquero, Genaro, "Magnitud y características de la inversión exterior en Puerto Rico", Revista de Ciencias Sociales, 8/2 (Río Piedras, 1964): 5-13.

Banco Internacional de Reconstrucción y Fomento, Informe sobre Cuba, La Habana, Banco Nacional de Cuba, 1951.

Baver, Sherrie L., The Political Economy of Colonialism: the State and Industrialization in Puerto Rico, London, Praeguer, 1993.

Bértola, Luis y José A. Ocampo, El desarrollo económico de América latina desde la independencia, México, Fondo de Cultura Económica, 2013. 
Bolívar Fresneda, José, "La economía de Puerto Rico durante la II Guerra Mundial, ¿capitalismo estatal o economía militar?”, Op. Cit., 18 (San Juan, P. R., 20072008): 207-257.

Bolívar Fresneda, José, "Los inicios del programa industrial de Puerto Rico, 19421948”, Guy Pierre (ed.), Histoire économique de la Caraibe (1880-1950), [Port-au-Prince], Éditions de L'Université d'État d'Haiti, 2012: 323-348.

Cassá, Roberto, Capitalismo y dictadura, Santo Domingo, Editora de la UASD, 1982.

Conferencia para el progreso de la economía nacional, La Habana, 1949.

Cuba, Ministerio de Hacienda, Informe al Consejo de Ministros, La Habana, 1959.

Curet, Eliézer, Economía política de Puerto Rico, 1950-2000, San Juan, M.A.C., 2003.

Dietz, James L., Historia económica de Puerto Rico, Rio Piedras, Huracán, 1989.

González, Carmen, "El tiempo de los príncipes del azúcar: la discursividad azucarera en Puerto Rico, 1920-1939", Tesis doctoral. (Universidad de Puerto Rico, Río Piedras, 2000).

Marquéz, María Antonia, Estado y economía en la antesala de la revolución, 19401952, La Habana, Editorial de Ciencias Sociales, 1994.

Marquéz, María Antonia, Las industrias menores: empresarios y empresas en Cuba (1880-1920), La Habana, Ciencias Sociales, 2006.

Martínez Sáenz, Joaquín, Por la independencia económica de Cuba, La Habana, 1959.

Moya Pons, Frank, Empresarios en conflicto: políticas de industrialización y sustitución de importaciones en República Dominicana, Santo Domingo, Fondo para el avance de las Ciencias Sociales, 1992.

Pantojas García, Emilio, Development Strategies as Ideology. Puerto Rico's Export-led Industrialization Experience, Boulder, Lynne Rienner Publishers, 1990.

Pérez-López, Jorge, "An Index of Cuban Industrial Output, 1930-58”, J. W. Wilkie y K. Riddle, (eds.), Quantitative Latin American Studies: Methods and Findings, Los Angeles, UCLA, 1977: 37-72.

Pino Santos, Óscar, Los años 50, La Habana, Instituto Cubano del Libro, 2001.

Wells, Henry, The Modernization of Puerto Rico, Cambridge, Harvard University Press, 1969.

Wiarda, Howard, Dictatorship and Development. The Methods of Control in Trujillo's Dominican Republic, Gainesville, University of Florida Press, 1968.

Zanetti, Oscar, Esplendor y decadencia del azúcar en las Antillas hispanas, La Habana, Ciencias Sociales, 2012.

Fecha de recepción: 2 de enero de 2015.

Fecha de aceptación: 10 de febrero de 2015. 


\section{The Beginning of the Industrialization of the Spanish Antilles}

With the worldwide crises of 1929 as a starting point, industrialization becomes the dominating trend in Latin American economies. Though the Spanish Antilles were no exception, the process did take on particular notes, both regarding what took place on the continent and within the islands themselves. The industrial development that is barely noticeable in the 1930s, gains momentum under the effects of World War II and accelerates under the aegis of the State in the postwar 1950s, having very distinct profiles in each country.

KEY WORDS: Antilles; Dominican Republic; Puerto Rico; Cuba; Industrialization; Economic Policy; 1929-1960. 